\section{Research Square}

\title{
Frailty index-predicted mortality is moderated by health-related behaviors: a 4-year community-based longitudinal-cohort study
}

\section{Limei Huang}

Centers for Disease Control and Prevention

Hao Chen ( $\sim$ haochen18@fudan.edu.cn)

Fudan University School of Public Health https://orcid.org/0000-0002-7886-7822

Bo Ye

Centers for Disease Control and Prevention

Shige Qi

Centers for Disease Control and Prevention

Ye Ruan

Centers for Disease Control and Prevention

Xiuqin Chen

Centers for Disease Control and Prevention

Guomei Ding

Centers for Disease Control and Prevention

Jihui Fei

Centers for Disease Control and Prevention

Yongquan Shen

Centers for Disease Control and Prevention

Junling Gao

Fudan University

Yan Shi

Centers for Disease Control and Prevention

\section{Research article}

Keywords: frailty index, mortality, health-related behaviors, cohort study

Posted Date: January 24th, 2020

DOI: https://doi.org/10.21203/rs.2.21751/v1 
License: (c) (i) This work is licensed under a Creative Commons Attribution 4.0 International License. Read Full License 


\section{Abstract}

To explore the separate and joint associations between frailty and long-term, all-cause mortality with health-related behaviors in older adults. We enrolled a total of 4050 community residents age $\geq 60$ years from Songjiang District, Shanghai, China, and followed up with them every year from 2015 to 2018.Based on the standard procedure for creating an $\mathrm{Fl}$, we developed one containing 28 measured variables. Survival analyses were used to examine the risk ratios (RRs) between frailty and 4-year mortality; hazard ratios (HRs) were obtained and adjusted for gender and age. Over an average follow-up time of $1107.56 \pm$ 144.43 days, $216(5.4 \%)$ participants died. Of all participants, $71.7 \%$ were non-frail ( $F I=0-0.1), 23.2 \%$ were pre-frail $(\mathrm{FI}=0.1-0.2)$, and $5.1 \%$ were frail $\left(\mathrm{FI}^{3} 0.2\right)$. Multivariate $\mathrm{HRs}$ (with $95 \%$ confidence intervals [Cls]) for all-cause mortality were $1.58(1.06-2.34)$ and $2.63(1.52-4.55)$ for moderate (FI 0.1-0.2) and severe ( $\mathrm{FI}>0.2)$ frailty, respectively, compared with mild frailty $(<0.1)$. Risk of death for severely frail participants who were physically inactive $(H R=3.40 ; 95 \% \mathrm{Cl}, 1.78-6.50 ; \mathrm{P}<0.001)$ was $105 \%$, much higher than for severely frail participants who performed physical exercise $(\mathrm{HR}=2.34 ; 95 \% \mathrm{Cl}, 1.35-4.09$; $P<0.01)$. Similarly, among severely frail participants, those who were socially inactive $(\mathrm{HR}=5.77 ; 95 \% \mathrm{Cl}$, $2.69-12.38 ; P<0.01$ ) were $344 \%$ more likely to die than those who regularly participated in social activities $(\mathrm{HR}=2.33 ; 95 \% \mathrm{Cl}, 1.42-3.86 ; \mathrm{P}<0.01)$.

\section{Introduction}

Frailty is a geriatric syndrome of nonspecific vulnerability to adverse outcomes (e.g., mortality, institutionalization, falls, hospitalization) resulting from the deregulation of multiple physiological-system factors associated with advancing age[1-4]. The overall weighted prevalence of frailty is $10.7 \%$ (range, 4.0-59.1\%), as reported in a systemic review that included 61,500 community-dwelling adults age $\geq 65$ years[5]. Empirically, the incidence and associated adverse health outcomes of frailty are expected to increase as the population ages. The public-health implications of frailty have been regarded as a significant and modifiable financial burden on health care services[6]. Therefore, it is advisable to prevent or slow the progression of frailty in order to advance healthy-life expectancy, and so a metric for frailty would be an important public-health indicator.

Two major common means of assessing frailty are the phenotypic approach and the frailty index (FI). The phenotypic approach, proposed by Fried et al., defines frailty as a distinct clinical syndrome measured by five criteria: unintentional weight loss, self-reported exhaustion, weakness (grip strength), slow walking speed, and low physical activity[7]. In contrast, the FI concentrates less on the specific syndrome and instead concentrates on the continuum of accumulating deficits (symptoms, functional impairments, diseases, and disabilities), reflecting the proportion of potential health deficits present in the individual $[8,9]$. These deficits across the physical, cognitive, and psychological domains[10] further emphasize frailty's important role in public health as a robust predictor of health changes, health care utilization, and death, thereby facilitating health monitoring and intervention[11-13]. We therefore employed the Fl in this study as a reflection of age-related developed processes. Rockwood et al. introduced the term "frailty" to describe observed heterogeneity in individuals of the same age that 
resulted in a decline in health or living status[14]. The deficit accumulation model of the FI specifically measures frailty as well as heterogeneity in risk of adverse outcomes; the latter is measured by all relevant indices.

Over the past 5 years, the number of studies on the Fl's validity for predicting mortality has grown, but the majority of subjects were hospitalized with various chronic diseases such as end-stage liver disease[15], HIV-related diseases[16], or Alzheimer disease[17]; or for operations such as spinal[18] or gastrointestinal surgery[19]. Round-the-clock care and enhancement of healthy longevity for elders who are frail or becoming frail, but living with their families or in the community, seems both more necessary and more difficult than temporarily providing treatment or nursing services for aged patients in hospitals, as individuals spend most of their lives in the former settings. Since the establishment of the frailty theory as an important factor in comprehensive geriatric assessments (CGAs), recognizing elders who are vulnerable to falls, hospitalization, and mortality in early-stage frailty has become the theory's most important usage in clinical practice[20]. From a health promotion perspective, providing health-related resources and education is critical and useful to maintaining the health of elders in the community, as it enables each elder to adopt a healthy lifestyle and behaviors[21]. A 10-year community intervention for frailty prevention conducted in Japan used a health education program to motivate older residents to improve their levels of physical activity (PA), nutrition, and social participation (SP), ultimately extending healthy-life expectancy at age 70 years by 1.2 years for women and 0.5 years for men[22]. Lifestyle and health behaviors also influence each older adult's various domains of accumulated deficits, which may contribute to FI heterogeneity across different geographies[23-25]. However, research examining the separate or joint associations among lifestyle, frailty, and long-term mortality in older adults, especially in developing countries[26], is scarce. Therefore, our study aimed to assess whether lifestyle (PA and SP) could compensate for the excess mortality associated with frailty.

\section{Materials And Methods}

\section{Study design and participants}

We used multi-stage random sampling to recruit 4050 participants from an investigation of chronic diseases and geriatric syndromes during 2015 (baseline) from Shanghai, representative of the noninstitutionalized population age $\geq 60$ years in Shanghai, China, from July 2015 to November 2018 . Random sampling methods was used to select four communities in two streets, then was used to select family addresses in which older residents lived in through a household registration information system. Trained personnel collected information at participants' homes via interviews, with the intention of investigating the associations among biological, psychological, and social aspects of elder health. Only $15(0.4 \%)$ respondents of the final study were lost to follow-up in this cohort. Written informed consent was obtained from each study participant and the Research Ethics Committee of researchers' institution, approved the study protocol.

\section{Frailty index construction}


We recorded the presence or absence of deficits, including continuous, ordinal, and binary variables associated with frailty. Initially, we identified variables similar to those used in other studies[27, 28]and in such indices as the Activities of Daily Living (ADL)[29], the Ascertain Dementia-8 (AD8)[30], and the Parkinson Disease Short Questionnaire (PDSI)[31]. The 28 items were listed in Table 1. Our FI evaluated comorbidities (medically diagnosed conditions) and self-reported health. All variables could be integrated into the Fl if they satisfied the following 5 criteria suggested by Rockwood: (1) A variable must be a deficit associated with health status; (2) its prevalence must generally increase with age; (3) it must not become highly prevalent at too early a life stage; (4) deficits must cover a range of systems; and (5) if a single FI is to be used serially on the same people, the items it comprises must remain the same from one iteration to the next[32]. Therefore, we defined our $\mathrm{FI}$ as the proportion an individual had of the 28 deficits we included. Binary variables indicated the presence/absence of a particular deficit; a score of 1 was given for presence, a score of 0 for absence. For each ADL item with 2 intermediate responses (e.g. "self-care," "self-care deficit," "self-care assistance," "dependent on others"), we used additional values of 0.33 and 0.67. For the AD8 and PDSI, according to impairment status, we assigned a score of 1 for dementia (cutoff: AD8 score $\geq 2$ according to the clinical dementia rating standard) or Parkinson (cutoff: PDSI score $\geq 4$ ), with 0 denoting the absence of both cognitive impairment and Parkinson[30, 31]. The FI cutoff value of 0.2 is recognized by multiple frailty measures to mean "approaching a frail state[33]." In our study, the cutoff point 0.1 , representing pre-frailty, could predict 3-year mortality as well as frailty status, according to receiver operating characteristic $(\mathrm{ROC})$ curve analysis (area under the curve $[A U C]=0.66$; sensitivity $=0.56$; specificity $=0.73)$. Therefore, we used 3 levels $(0-0.1$, non-frailty; $0.1-0.2$, pre-frailty; $\geq 0.2$, frailty) to illustrate the association between $\mathrm{Fl}$ and mortality. 
Table 1

List of the 28 items in the frailty index.

\begin{tabular}{|ll|}
\hline Activities of daily living $^{\text {a }}$ & Medically diagnosed conditions ${ }^{\text {a }}$ \\
\hline 1. Problems getting dressed & 16. High blood pressure \\
\hline 2. Problems bathing & 17. Coronary heart disease \\
\hline 3. Problems walking indoors & 18. History of stroke \\
\hline 4. Toileting problems & 19. Chronic bronchitis \\
\hline 5. Problems getting in and out of bed & 20. Diabetes mellitus \\
\hline 6. Problems with urine and feces control & 21. Cataracts \\
\hline 7. Problems eating & 22. Hearing loss \\
\hline 8. Problems making phone calls & 23. Urinary incontinence \\
\hline 9. Problems shopping & Self-reported health ${ }^{\text {b }}$ \\
\hline 10. Problems cooking & 24. Problems with sense of smell \\
\hline 11. Problems doing housework & 25. Constipation \\
\hline 12. Problems doing laundry & 26. Problems with sleeping \\
\hline 13. Problems taking bus & Comprehensive assessment ${ }^{\text {a }}$ \\
\hline 14. Problems taking medicine & 27. Ascertain Dementia-8 \\
\hline 15. Problems handling money & 28. Parkinson Disease Short Questionnaire \\
\hline a Binary variables; values 0 or 1 . $^{b}$ Four-category variables; values $0,0.335,0.67$, and 1. \\
\hline
\end{tabular}

\section{Moderator variables}

We assessed PA using validated single questions, which are habitually used to monitor the prevalence of physical activity[34]: "How often do you perform leisure-time activities, such as playing ball, running, fast walking, or qigong? (Average physical-activity time must exceed 10 minutes per day.)" Participants rated their PA levels as (1) inactive, (2) several times a month, (3) 3-4x/week, or (4) almost every day. We chose to integrate these 4 categories into a binary variable to intelligibly explain the association between PA and frailty: physically inactive versus physically active (several times a month, $3-4 \times /$ week, and almost every day). SP was assessed by a single question that we designed: "How often do you participate in social activities, such as those organized by your local university, by the community, or by other elderly people?" Participants rated their SP as (1) inactive, (2) several times a year, (3) several times a month, or (4) several times a week. As with PA, we integrated the 4 SP categories into a binary variable: inactive versus active SP. 


\section{Mortality ascertainment}

Mortality status and date of death were obtained from the Death Surveillance System of local institution for all participants after each follow-up. Time to death or censoring was calculated for each participant.

\section{Covariates}

Covariates were chosen from single factor analysis associated with frailty status, including age, gender, educational attachment (illiteracy, primary, $\geq$ junior school), marriage status (spinsterhood, married), tobacco smoking and alcohol consumption (never, sometimes, every day).

\section{Data analysis}

Numerical variables are presented as mean \pm standard deviation (SD), categorical variables as number (percentage). We calculated the FI distribution of study participants' sociodemographic characteristics using Student's t test or analysis of variance (ANOVA). Association between all-cause mortality and frailty status (non-frail, pre-frail, or frail) was summarized using hazard ratios (HRs) and their $95 \%$ confidence intervals (Cls) obtained from Cox regression. We fitted 2 models with progressive adjustments for potential covariates. To examine the separate association between frailty and all-cause mortality, we stratified Cox regression analysis by level of health behaviors, including PA and SP. Next, we examined the modifier effects of PA and SP by incorporating an interaction term into the Cox models. Statistical significance was set at $\mathrm{P}<0.05$, and all tests were 2-sided. We performed all analyses using SPSS software version 22.0 (SPSS, Inc., Chicago, Illinois, US) and R software version 3.5.3 (R; https://www.rproject.org/).

\section{Results}

The analytic cohort comprised 4050 participants (mean age $69.48 \pm 7.13$ years; $43.6 \%$ male). During the study period, with average follow-up of $1107.56 \pm 144.43$ days, 216 deaths occurred (5.6\%). The constructed FI had a median value of 0.08 (range, $0-0.76$ ) in the target population (Fig. 1); as a result, $71.7 \%$ of participants were non-frail $(\mathrm{FI}=0-0.1), 23.2 \%$ were pre-frail $(\mathrm{FI}=0.1-0.2)$, and $5.1 \%$ were frail $(\mathrm{FI}=\geq 0.2)$.

Table 2 summarizes participants' sociodemographic characteristics by these 3 frailty levels. There were proportionally more female, unmarried, illiterate, never-smoking, never-drinking, physically active, and socially active participants on all 3 levels $(P<0.05)$. In age- and gender-adjusted analyses, pre-frail participants were $45 \%$ more likely than non-frail ones to die $(\mathrm{HR}=1.45 ; 95 \% \mathrm{Cl}, 1.05-2.01 ; \mathrm{P}=0.026)$, while frail ones were more than 3 times as likely $(H R=3.15 ; 95 \% \mathrm{Cl}, 2.11-4.70 ; \mathrm{P}<0.001)$. The results were similar in fully adjusted analyses (pre-frail: $\mathrm{HR}=1.58 ; 95 \% \mathrm{Cl}, 1.06-2.34, \mathrm{P}=0.024$; frail: $\mathrm{HR}=2.63$; $95 \% \mathrm{Cl}, 1.52-4.55 ; \mathrm{P}=0.001$; Fig. 2). 
Table 2

Participant sociodemographic characteristics stratified by the 3 levels of the frailty index.

\begin{tabular}{|c|c|c|c|c|}
\hline & $\begin{array}{l}\text { Non-frail } \\
(n=2865)\end{array}$ & $\begin{array}{l}\text { Pre-frail } \\
(n=929)\end{array}$ & $\begin{array}{l}\text { Frail } \\
(n=202)\end{array}$ & $\chi 2, P$ \\
\hline Age & $67.96 \pm 6.31$ & $72.21 \pm 7.27$ & $76.51 \pm 7.92$ & $<0.001$ \\
\hline \multicolumn{5}{|l|}{ Gender } \\
\hline Male & $1388(79.8)$ & 294 (16.9) & $58(3.3)$ & 99.58 \\
\hline Female & 1477 (65.5) & $635(28.1)$ & $144(6.4)$ & $<0.001$ \\
\hline \multicolumn{5}{|l|}{ Marital status } \\
\hline Single & $469(58.0)$ & 248 (30.7) & 391 (11.3) & 127.61 \\
\hline Married & $2396(75.2)$ & $681(21.4)$ & $111(3.5)$ & $<0.001$ \\
\hline \multicolumn{5}{|l|}{ Educational level } \\
\hline Illiteracy & $1420(62.9)$ & 669 (29.6) & $168(7.4)$ & 207.30 \\
\hline Primary school & 988 (83.9) & $172(14.6)$ & $18(1.5)$ & $<0.001$ \\
\hline$\geq$ Junior school & 457 (81.5) & $88(15.7)$ & $16(2.9)$ & \\
\hline \multicolumn{5}{|l|}{ Smoking } \\
\hline Never & 2125 (68.2) & $813(25.8)$ & $191(6.1)$ & 100.36 \\
\hline Sometimes & $39(73.6)$ & $11(20.8)$ & $3(5.7)$ & $<0.001$ \\
\hline Daily & $674(85.6)$ & 105 (13.3) & $8(1.0)$ & \\
\hline \multicolumn{5}{|l|}{ Drinking } \\
\hline Never & $2226(68.6)$ & $824(25.4)$ & $196(6.0)$ & 200.30 \\
\hline Sometimes & 139 (79.9) & $33(19.0)$ & $2(1.1)$ & $<0.001$ \\
\hline Daily & $500(86.5)$ & $72(12.5)$ & $4(0.7)$ & \\
\hline \multicolumn{5}{|c|}{ Physical activities } \\
\hline Inactive & $591(67.0)$ & $216(24.5)$ & $75(8.5)$ & 30.85 \\
\hline Active & $2274(73.0)$ & 713 (22.9) & $127(4.1)$ & $<0.001$ \\
\hline \multicolumn{5}{|c|}{ Social participation } \\
\hline Inactive & $512(66.6)$ & 199 (25.9) & $58(7.5)$ & 17.96 \\
\hline Active & $2353(72.9)$ & 730 (22.6) & $144(4.5)$ & $<0.001$ \\
\hline
\end{tabular}


As shown in Table 3, when examining the association between frailty and mortality according to PA, we found clear dose-response associations in both groups. In the fully adjusted stratification analysis model, the hazard risk of death in frail participants who were physically inactive $(\mathrm{HR}=3.99 ; 95 \% \mathrm{Cl}, 2.14-$ 7.44; $\mathrm{P}<0.001)$ was $165 \%$, much higher than in frail participants who did perform physical exercise $(\mathrm{HR}=$ $2.34 ; 95 \% \mathrm{Cl}, 1.35-4.09 ; \mathrm{P}<0.01)$. In further analysis of the interaction term between frailty and physical activity, physical activity did modify the main effect of frailty on mortality (all-cause mortality: $\mathrm{P}$ for interaction $=0.004$ ). A similar association between SP and frailty is shown in Table 4. In the fully adjusted stratification analysis model, frail elders who were socially inactive $(\mathrm{HR}=5.77 ; 95 \% \mathrm{Cl}, 2.69-12.38 ; \mathrm{P}<$ 0.01 ) were $344 \%$ more likely to die than frail participants who regularly participated in social activities $(\mathrm{HR}=2.33 ; 95 \% \mathrm{Cl}, 1.42-3.86 ; \mathrm{P}<0.01)$. In further analysis of the interaction term, SP also modified the main effect of frailty on mortality (all-cause mortality: $\mathrm{P}$ for interaction $<0.001$ ).

Table 3

All-cause mortality as predicted by FI and stratified by physical activity (PA).

\begin{tabular}{|c|c|c|c|}
\hline \multirow[t]{2}{*}{ PA } & \multicolumn{3}{|l|}{ Frailty Index } \\
\hline & Non-frail & Pre-frail & Frail \\
\hline \multicolumn{4}{|l|}{ Inactive } \\
\hline Died/total, n/N & 27/589 (4.6\%) & $20 / 215$ (9.3\%) & 24/73 (32.9\%) \\
\hline Model 1, HR (95\% Cl) & 1 & $1.76(0.96-3.22)$ & $3.99(2.14-7.44)^{\star \star \star}$ \\
\hline Model 2, HR (95\% Cl) & 1 & $1.71(0.93-3.15)$ & $3.40(1.78-6.50)^{\star \star \star}$ \\
\hline \multicolumn{4}{|l|}{ Active } \\
\hline Died/total, n/N & $72 / 2272(3.2 \%)$ & $46 / 712(6.5 \%)$ & 18/127 (14.2\%) \\
\hline Model 1, HR (95\% Cl) & 1 & $1.36(0.92-2.00)$ & $2.39(1.37,4.16)^{\star \star}$ \\
\hline Model 2, HR $(95 \% \mathrm{Cl})$ & 1 & $1.31(0.89-1.94)$ & $2.34(1.35,4.09)^{\star \star}$ \\
\hline
\end{tabular}


Table 4

All-cause mortality as predicted by FI and stratified by social participation (SP).

\begin{tabular}{|c|c|c|c|}
\hline \multirow[t]{2}{*}{ SP } & \multicolumn{3}{|l|}{ Frailty Index } \\
\hline & Non-frail & Pre-frail & Frail \\
\hline \multicolumn{4}{|l|}{ Inactive } \\
\hline Died/total, n/N & 17/512 (3.3\%) & 13/199 (6.5\%) & 17/56 (30.4\%) \\
\hline Model 1, HR $(95 \% \mathrm{Cl})$ & 1 & $1.48(0.71-3.10)$ & $5.90(2.83-12.30)^{\star \star \star}$ \\
\hline Model 2, HR $(95 \% \mathrm{Cl})$ & 1 & $1.42(0.68-3.00)$ & $5.77(2.69-12.38)^{\star \star \star}$ \\
\hline \multicolumn{4}{|l|}{ Active } \\
\hline Died/total, n/N & $82 / 2349(3.5 \%)$ & $53 / 728(7.8 \%)$ & $25 / 144(17.4 \%)$ \\
\hline Model 1, HR $(95 \% \mathrm{Cl})$ & 1 & $1.44(1.01-2.08)^{*}$ & $2.42(1.47-3.97)^{\star \star \star}$ \\
\hline Model 2, HR $(95 \% \mathrm{Cl})$ & 1 & $1.39(0.96-2.01)$ & $2.33(1.42-3.86)^{\star *}$ \\
\hline
\end{tabular}

\section{Discussion}

The baseline frailty prevalence of $5.1 \%$ in the 4050 elders we studied was in line with previous community population-based research, which found that frailty among participants was $6.6 \%$ over 5 years of followup in Mexican Americans from the Hispanic established populations[35] and 5.4\% in China's general population[36]. Among our participants, older women seemed more vulnerable to accumulated deficits than older men, as another study also found[37]. Women's tendency to become severely frail in later life could be explained by their higher probability of functional disability, which is a main measure of physical deficits[38]. Our results also suggested that participants with lower educational attainment were more likely to be severely frail, which was in agreement with a previous study that older adults with lower educational attainment were at increased risk of worsening frailty over a 2-year period[39]. A plausible reason is that older adults are more likely to experience bereavement; both widowers and widows reportedly have high individual HRs for mortality[40].

Frailty is a dynamic process characterized by frequent transitions between levels of frailty over time; natural transitions to more-severe levels are more common than transitions to less-severe levels[41]. However, evidence is insufficient to support any efficacious and economical strategy to postpone this degradation process. The finding that performing PA at an advanced age lowered participants' risk of mortality, even compared with inactive participants at identical frailty levels, was consistent with recent 
research[42-44]. In a total sample of 498,135 participants conducted by the UK Biobank, the highest risk of death was found in participants with the lowest PA level, and the risk of mortality increased as the PA quantile decreased[45]. The possible explanation may contribute to the beneficial effect that PA was demonstrated can reduce the incidence of chronic diseases[46], Alzheimer disease[47], Parkinson disease[48], and disability [46], which are all FI components, and can reduce mortality in turn. Our research also suggested that SP actively reduced the probability of mortality approximately eightfold in frail participants compared with those who seldom participated in social activities. Although a few studies have focused on the moderating effect of SP on the association between frailty and mortality, several others provide assertive evidence that might explain the mechanism behind the favorable effect of PA. SP inactivity, as a domain of social frailty, is associated with the frailty development process[39], which in turn can influence long-term SP level[49]. Social frailty linked to dementia, subjective-memory decline, depression, and cognitive impairment poses a higher risk of 8-year mortality in participants who are socially frail than in those who are not[50]. Moreover, SP is critical to the social environment, a broad concept that also includes social networks, social support, and neighborhood characteristics. There is evidence that a good social environment has a beneficial effect on frailty in later life, meaning that mortality could be reduced by ensuring that elders obtain health-related resources[51].

This study has some limitations. Since a single question was used to assess PA and SP levels to some extent, the metric might need to be more specific and multidimensional in further research. Another limitation was the low sensitivity $(<0.6)$ for frailty on the ROC curve, due to the low proportion of participants who did not suffer from a high level of deficits in our study. Furthermore, all variables in FI were self-reported through participants while several cervix data were excluded because of non-correlates to age.

\section{Conclusions And Implications}

Among community-dwelling persons age $\geq 60$ years in Shanghai, China, pre-frailty and frailty were associated with much higher all-cause mortality than robust health over 3 years of follow-up, but in frail individuals, participation in PA and SP was associated with lower mortality risk compared with those who were physically and socially inactive. These findings suggested that the FI we created by counting accumulated deficits in elders could predict all-cause mortality and that PA and SP might partly moderate frailty-influenced risk of mortality in older adults.

\section{Declarations}

Conflicts of Interest: The authors declare no conflict interest.

Funding sources: This work was supported by the National key R\&D Program of China (grant number:2018YFC2002001). 
Acknowledgements: We gratefully thank all participants and the general practitioners for their cooperation.

\section{References}

1.

Roe L, Normand C, Wren MA, Browne J, O'Halloran AM. The impact of frailty on healthcare utilisation in Ireland: evidence from the Irish longitudinal study on ageing. BMC Geriatr. 2017;17(1):203.

2.

Garcia-Gonzalez JJ, Garcia-Pena C, Franco-Marina F, Gutierrez-Robledo LM. A frailty index to predict the mortality risk in a population of senior Mexican adults. BMC Geriatr. 2009;9:47.

3.

Fried LP, Ferrucci L, Darer J, Williamson JD, Anderson G. Untangling the concepts of disability, frailty, and comorbidity: implications for improved targeting and care. J Gerontol A Biol Sci Med Sci. 2004;59(3):255-63.

4.

Ensrud KE, Ewing SK, Taylor BC, Fink HA, Stone KL, Cauley JA, Tracy JK, Hochberg MC, Rodondi N, Cawthon PM, et al. Frailty and risk of falls, fracture, and mortality in older women: the study of osteoporotic fractures. J Gerontol A Biol Sci Med Sci. 2007;62(7):744-51.

5 .

Collard RM, Boter H, Schoevers RA, Oude Voshaar RC. Prevalence of frailty in community-dwelling older persons: a systematic review. J Am Geriatr Soc. 2012;60(8):1487-92.

6.

Janssen I, Shepard DS, Katzmarzyk PT, Roubenoff R. The healthcare costs of sarcopenia in the United States. J Am Geriatr Soc. 2004;52(1):80-5.

7.

Fried LP, Tangen CM, Walston J, Newman AB, Hirsch C, Gottdiener J, Seeman T, Tracy R, Kop WJ, Burke G, et al. Frailty in older adults: evidence for a phenotype. J Gerontol A Biol Sci Med Sci. 2001;56(3):M14656.

8.

Song X, Mitnitski A, Rockwood K. Prevalence and 10-year outcomes of frailty in older adults in relation to deficit accumulation. J Am Geriatr Soc. 2010;58(4):681-7.

9.

Rockwood K, Andrew M, Mitnitski A. A comparison of two approaches to measuring frailty in elderly people. J Gerontol A Biol Sci Med Sci. 2007;62(7):738-43.

10.

Kojima G, lliffe S, Walters K. Frailty index as a predictor of mortality: a systematic review and metaanalysis. Age Ageing. 2018;47(2):193-200.

11. 
Schoufour JD, Evenhuis HM, Echteld MA. The impact of frailty on care intensity in older people with intellectual disabilities. Res Dev Disabil. 2014;35(12):3455-61.

12.

Kulminski A, Yashin A, Ukraintseva S, Akushevich I, Arbeev K, Land K, Manton K. Accumulation of health disorders as a systemic measure of aging: Findings from the NLTCS data. Mech Ageing Dev. 2006;127(11):840-8.

13.

Goggins WB, Woo J, Sham A, Ho SC. Frailty index as a measure of biological age in a Chinese population. J Gerontol a-Biol. 2005;60(8):1046-51.

14.

Rockwood K, Mitnitski A. Resilience and frailty: Further steps, best taken together. European Geriatric Medicine. 2015;6(5):405-7.

15.

Lai JC, Covinsky KE, Dodge JL, Boscardin WJ, Segev DL, Roberts JP, Feng S. Development of a novel frailty index to predict mortality in patients with end-stage liver disease. Hepatology. 2017;66(2):564-74. 16.

Guaraldi G, Brothers TD, Zona S, Stentarelli C, Carli F, Malagoli A, Santoro A, Menozzi M, Mussi C, Mussini $\mathrm{C}$, et al. A frailty index predicts survival and incident multimorbidity independent of markers of HIV disease severity. AIDS. 2015;29(13):1633-41.

17.

Kelaiditi E, Andrieu S, Cantet C, Vellas B, Cesari M, Group ID. Frailty Index and Incident Mortality, Hospitalization, and Institutionalization in Alzheimer's Disease: Data From the ICTUS Study. J Gerontol A Biol Sci Med Sci. 2016;71(4):543-8.

18.

Ali R, Schwalb JM, Nerenz DR, Antoine HJ, Rubinfeld I. Use of the modified frailty index to predict 30-day morbidity and mortality from spine surgery. J Neurosurg Spine. 2016;25(4):537-41.

19.

Buettner S, Wagner D, Kim Y, Margonis GA, Makary MA, Wilson A, Sasaki K, Amini N, Gani F, Pawlik TM. Inclusion of Sarcopenia Outperforms the Modified Frailty Index in Predicting 1-Year Mortality among 1,326 Patients Undergoing Gastrointestinal Surgery for a Malignant Indication. J Am Coll Surg. 2016;222(4):397-407 e392.

20.

van Kempen JA, Melis RJ, Perry M, Schers HJ, Rikkert MG. Diagnosis of frailty after a Comprehensive Geriatric Assessment: differences between family physicians and geriatricians. J Am Board Fam Med. 2015;28(2):240-8.

21.

Mozaffarian D, Afshin A, Benowitz NL, Bittner V, Daniels SR, Franch HA, Jacobs DR Jr, Kraus WE, KrisEtherton PM, Krummel DA, et al. Population approaches to improve diet, physical activity, and smoking habits: a scientific statement from the American Heart Association. Circulation. 2012;126(12):1514-63. 22. 
Shinkai S, Yoshida H, Taniguchi Y, Murayama H, Nishi M, Amano H, Nofuji Y, Seino S, Fujiwara Y. Public health approach to preventing frailty in the community and its effect on healthy aging in Japan. Geriatr Gerontol Int. 2016;16(Suppl 1):87-97.

23.

Shi J, Song X, Yu P, Tang Z, Mitnitski A, Fang X, Rockwood K. Analysis of frailty and survival from late middle age in the Beijing Longitudinal Study of Aging. BMC Geriatr. 2011;11:17.

24.

Theou O, Blodgett JM, Godin J, Rockwood K. Association between sedentary time and mortality across levels of frailty. CMAJ. 2017;189(33):E1056-64.

25.

Brinkman S, Voortman T, Kiefte-de Jong JC, van Rooij FJA, Ikram MA, Rivadeneira F, Franco OH, Schoufour JD. The association between lifestyle and overall health, using the frailty index. Arch Gerontol Geriatr. 2018;76:85-91.

26.

Gu D, Dupre ME, Sautter J, Zhu H, Liu Y, Yi Z. Frailty and mortality among Chinese at advanced ages. J Gerontol B Psychol Sci Soc Sci. 2009;64(2):279-89.

27.

Mitnitski AB, Song X, Rockwood K. The estimation of relative fitness and frailty in community-dwelling older adults using self-report data. J Gerontol A Biol Sci Med Sci. 2004;59(6):M627-32. 28.

Ma L, Zhang L, Tang Z, Sun F, Diao L, Wang J, Zhao X, Ge G. Use of the frailty index in evaluating the prognosis of older people in Beijing: A cohort study with an 8-year follow-up. Arch Gerontol Geriatr. 2016;64:172-7.

29.

Yang F, Gu D. Predictability of frailty index and its components on mortality in older adults in China. BMC Geriatr. 2016;16:145.

30.

Galvin JE, Roe CM, Powlishta KK, Coats MA, Muich SJ, Grant E, Miller JP, Storandt M, Morris JC. AD8:A brief informant interview to detect dementia. Neurology. 2005;65(4):559-64.

31.

Setthawatcharawanich S, Sathirapanya P, Phabphal K, Limapichat K. Short questionnaire for Parkinson's disease as a screening instrument. Clin Neurol Neurosurg. 2011;113(10):885-8.

32.

Searle SD, Mitnitski A, Gahbauer EA, Gill TM, Rockwood K. A standard procedure for creating a frailty index. BMC Geriatr. 2008;8:24.

33.

Patel KV, Brennan KL, Brennan ML, Jupiter DC, Shar A, Davis ML. Association of a modified frailty index with mortality after femoral neck fracture in patients aged 60 years and older. Clin Orthop Relat Res. 2014;472(3):1010-7.

34. 
Gill DP, Jones GR, Zou GY, Speechley M. Using a single question to assess physical activity in older adults: a reliability and validity study. Bmc Med Res Methodol 2012, 12.

35 .

Ostir GV, Ottenbacher KJ, Markides KS. Onset of frailty in older adults and the protective role of positive affect. Psychol Aging. 2004;19(3):402-8.

36.

YU RTNI. Telomere length is not associated with frailty in older Chinese elderly:cross-sectional and longitudinal analysis. MechAgeing Dev. 2015;152:74-9.

37.

Mitnitski AB, Mogilner AJ, MacKnight C, Rockwood K. The mortality rate as a function of accumulated deficits in a frailty index. Mech Ageing Dev. 2002;123(11):1457-60.

38 .

Zhong Y, Wang J, Nicholas S. Gender, childhood and adult socioeconomic inequalities in functional disability among Chinese older adults. Int J Equity Health. 2017;16(1):165.

39.

Etman A, Kamphuis CBM, van der Cammen TJM, Burdorf A, van Lenthe FJ. Do lifestyle, health and social participation mediate educational inequalities in frailty worsening? Eur J Pub Health. 2015;25(2):345-50. 40.

Ytterstad E. Frailty in Survival Analysis of Widowhood Mortality. Journal of Probability Statistics. 2018;2018:1-5.

41.

Gill TM, Gahbauer EA, Allore HG, Han L. Transitions between frailty states among community-living older persons. Arch Intern Med. 2006;166(4):418-23.

42.

White DK, Neogi T, Nevitt MC, Peloquin CE, Zhu Y, Boudreau RM, Cauley JA, Ferrucci L, Harris TB, Satterfield SM, et al. Trajectories of gait speed predict mortality in well-functioning older adults: the Health, Aging and Body Composition study. J Gerontol A Biol Sci Med Sci. 2013;68(4):456-64.

43.

Ma L, Wang J, Tang Z, Chan P. Simple Physical Activity Index Predicts Prognosis in Older Adults: Beijing Longitudinal Study of Aging. J Nutr Health Aging. 2018;22(7):854-60.

44.

Higueras-Fresnillo S, Cabanas-Sanchez V, Lopez-Garcia E, Esteban-Cornejo I, Banegas JR, Sadarangani KP, Rodriguez-Artalejo F, Martinez-Gomez D. Physical Activity and Association Between Frailty and AllCause and Cardiovascular Mortality in Older Adults: Population-Based Prospective Cohort Study. J Am Geriatr Soc. 2018;66(11):2097-103.

45 .

Celis-Morales CA, Lyall DM, Anderson J, Iliodromiti S, Fan Y, Ntuk UE, Mackay DF, Pell JP, Sattar N, Gill JM. The association between physical activity and risk of mortality is modulated by grip strength and cardiorespiratory fitness: evidence from 498135 UK-Biobank participants. Eur Heart J. 2017;38(2):11622. 
46.

Gretebeck RJ, Ferraro KF, Black DR, Holland K, Gretebeck KA. Longitudinal change in physical activity and disability in adults. Am J Health Behav. 2012;36(3):385-94.

47.

Varma VR, Watts A. Daily Physical Activity Patterns During the Early Stage of Alzheimer's Disease. J Alzheimers Dis. 2017;55(2):659-67.

48.

Fang X, Han D, Cheng Q, Zhang P, Zhao C, Min J, Wang F. Association of Levels of Physical Activity With Risk of Parkinson Disease: A Systematic Review and Meta-analysis. JAMA Netw Open. 2018;1(5):e182421.

49.

Pin S, Spini D. Impact of falling on social participation and social support trajectories in a middle-aged and elderly European sample. SSM Popul Health. 2016;2:382-9.

50 .

Ma L, Sun F, Tang Z. Social Frailty Is Associated with Physical Functioning, Cognition, and Depression, and Predicts Mortality. Journal of Nutrition Health Aging. 2018;22(8):989-95.

51 .

Duppen D, Van der Elst MCJ, Dury S, Lambotte D, De Donder L. D S: The Social Environment's Relationship With Frailty: Evidence From Existing Studies. J Appl Gerontol. 2019;38(1):3-26.

\section{Figures}




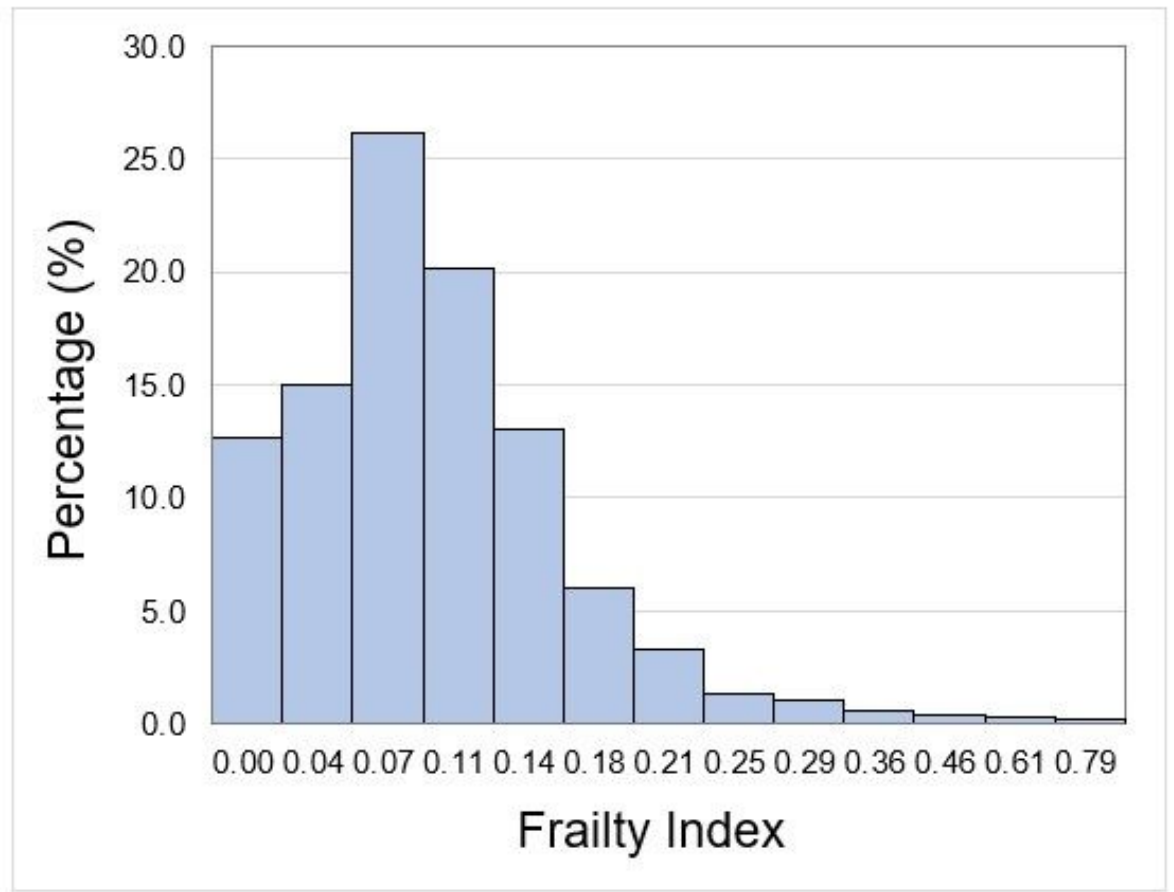

Figure 1. Frailty index distribution.

\section{Figure 1}

Frailty index distribution. 

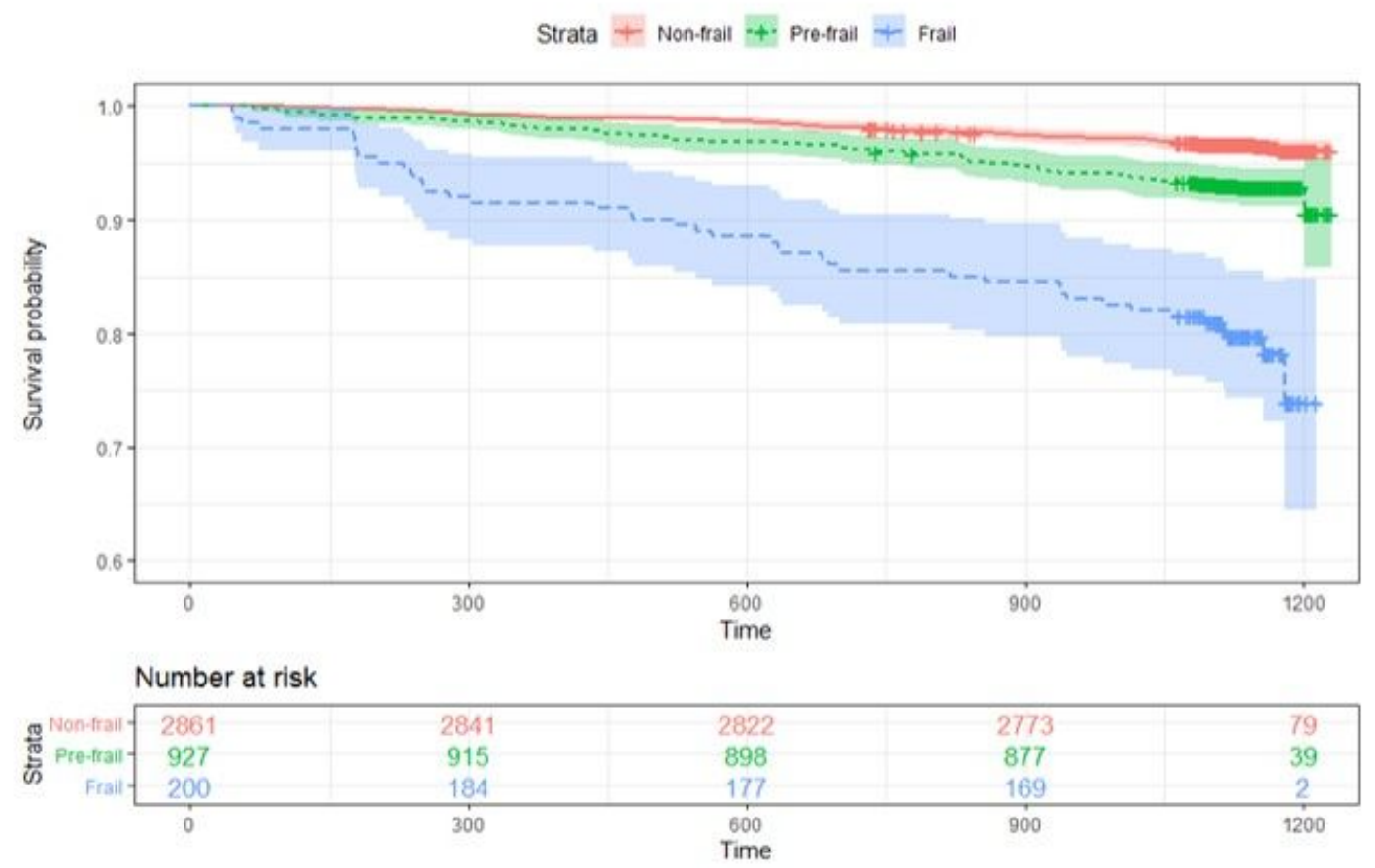

Figure 2. Kaplan-Meier survival analysis stratified by the 3 levels of the frailty index.

\section{Figure 2}

Kaplan-Meier survival analysis stratified by the 3 levels of the frailty index. 